Article

\title{
Inclusion of Ultra-Orthodox Students in Higher Education: A Case Study about Women Seminary in the Engineering College of Jerusalem
}

\author{
Michael Naor ${ }^{1, *(1)}$, Gavriel David Pinto ${ }^{2}$, Pini Davidov ${ }^{2}\left(\mathbb{D}\right.$, Julie Benaroch ${ }^{2}$ and Adit Kivel ${ }^{1,3}$ \\ 1 School of Business Adminitration, Hebrew University, Jerusalem 9190501, Israel \\ 2 Industrial Engineering and Management, Azrieli College of Engineering, Jerusalem 9103501, Israel; \\ gabipi@jce.ac.il (G.D.P.); pinida@jce.ac.il (P.D.); teboul.julie@gmail.com (J.B.) \\ 3 Lev Academic Center, Jerusalem College of Technology, Jerusalem 9116001, Israel; kivel@g.jct.ac.il \\ * Correspondence: michael.naor@mail.huji.ac.il
}

check for

updates

Citation: Naor, M.; Pinto, G.D.;

Davidov, P.; Benaroch, J.; Kivel, A. Inclusion of Ultra-Orthodox Students in Higher Education: A Case Study about Women Seminary in the Engineering College of Jerusalem. Educ. Sci. 2022, 12, 102. https:// doi.org/10.3390/educsci12020102

Academic Editors: Katherine

Marshall and Sudipta Roy

Received: 11 November 2021

Accepted: 29 January 2022

Published: 1 February 2022

Publisher's Note: MDPI stays neutral with regard to jurisdictional claims in published maps and institutional affiliations.

Copyright: (C) 2022 by the authors. Licensee MDPI, Basel, Switzerland. This article is an open access article distributed under the terms and conditions of the Creative Commons Attribution (CC BY) license (https:// creativecommons.org/licenses/by/ $4.0 /)$.

\begin{abstract}
This study examines how far the establishment of an ultra-orthodox (Haredi) women-only curriculum and learning environment crafted for their needs, such as supplementary Biblical studies, fosters students' enrollment and achievement in STEM. The methodology utilizes interviews with administrators accompanied by a Google questionnaire surveying students in order to compare the secular Azrieli College of Engineering with its new ultra-orthodox branch, Tmura Seminary, which aims to promote the acquisition by ultra-orthodox Jewish women of an engineering diploma so that they can find employment in the job market. This objective is significant because the ultra-orthodox community in Israel represents a unique family setting in which the men devote most of their workday to Judaic studies while the women are the breadwinners. The findings of the current study show that addressing the higher education gender gap by purposeful efforts to include ultra-orthodox women is indeed feasible. Still, it remains a challenging endeavor because besides being first-generation students subject to religious constraints, Haredi students are insufficiently prepared in mathematics and English before arriving at the campus, which requires that they participate in an intensive preacademic preparatory program. The analysis of results showed differences between ultra-orthodox and secular students in their motivation for study, sources of information about suitable education institutions, balancing work and family life priorities, financial need for scholarships, and career path, which is directed toward finding a job in the high-tech industry rather than continuing after graduation to pursue a Master-level degree.
\end{abstract}

Keywords: ultra-orthodox students; women in science; technology; engineering; and math; diversity; inclusiveness and accessibility to higher education in Israel

\section{Introduction}

As part of an attempt to increase religiously diverse populations on university campuses, ultra-orthodox students have started receiving long-overdue scholarly attention [1-3]. The unique challenges facing ultra-orthodox women who hail from fundamentalist denominations, minority groups, and sectarian religious communities require a rigorous investigation to comprehend their motivations, identify obstacles, and unveil achievements in pursuing higher education in order to establish a lasting supportive infrastructure.

Israel's colleges and universities are not producing engineering alumni at the pace the high-tech industry needs. Over $60 \%$ of Israeli tech start-ups complain about the struggle to recruit employees for their R\&D departments, as reported by the 2020 HighTech Human Capital Report from the Israel Innovation Authority and Start-Up Nation Central [4]. The report highlights vacancies for 13,000 tech job openings in Israel. Ultraorthodox (Haredi in Hebrew) women are a population segment that government officials expect to fill the vacancies in Science, Technology, Engineering, and Mathematics (STEM) 
education. Energized by the growing motivation of Haredi young professionals to join the Israeli workforce [5] and propelled by government incentives, there has been rapid growth in the bundle offering of academic degrees for the Haredi population in the 21st century. In addition to affirmative action stipends offered to Haredi students in Israeli universities/colleges, fourteen new government-funded academic tracks were established for Haredi students [6].

Our study on closing the gender gap by increasing the percentage of ultra-orthodox women in academic studies, specifically in STEM, has the potential to create social change in Israeli society by providing ultra-orthodox (Haredim) women with the necessary tools and skills to work as equals in Israel's competitive workforce and become partners in the start-up nation [7]. Moreover, this outcome may reduce the dependence on government and social welfare, as salary earnings in the Israeli tech arena are significantly higher than the country's average income. Interestingly, nearly $75 \%$ of ultra-orthodox women are actively working, which is an identical figure to the general population. Still, their monthly average wage of ILS 6170 (USD 1736) is below the ILS 9309 average of other Jewish women, and many ultra-orthodox women work only part-time.

The current study investigates several research questions. First, a comprehensive literature review juxtaposes the composition of orthodox women vs. secular women advancing after high school to study at college, the types of degrees they pursue, and why. Second, it attempts to validate whether general impediments mentioned in the literature, such as a lack of background in mathematics and English, as well as marriage at a young age, are indeed causing ultra-orthodox students to specifically drop out from STEM degrees and how they can be overcome. Third, it examines the antecedents for establishing a successful engineering program for ultra-orthodox women and its continuous management. This agenda discussion represents a paradigm shift in the way ultra-orthodox women are regarded in society by providing an opportunity for their academic potential to be unlocked, as, for decades, this population segment has been navigated by the Israeli educational system to study non-STEM subjects in order to be employed as teachers and social workers under the assumption that their lack of education in STEM during high school cannot be bridged. Our subject of investigation is ultra-orthodox women for two major reasons: first, in Israel, ultra-orthodox female college students currently surpass men at a ratio of 2:1 [8]; second, the scarce studies on ultra-orthodox women's educational status in traditional societies [9] indicate that women are agents of societal change [10], who have the power to revolutionize their community. Acquiring higher education can drive such a shift in the traditional mode of life and the family unit's structure, breaking the community leader's control over information flow and decision making [11,12].

\section{Literature Review}

The Israeli Jewish population is composed of several clusters: secularized, traditional, orthodox, and ultra-orthodox. In particular, the ultra-orthodox population is a growing segment in Israel, and it is projected to be $32 \%$ by 2065 . They represent approximately $11 \%$ of the Israeli population [13]. Based on recent statistics published by the Israel Democracy Institute [14], the ultra-orthodox segment (approximately 1.175 million) will double within the next 16 years, whereas the general Israeli population would take more than twice this time period (approximately 37 years) in order to experience the same growth rate. The term Haredi refers to multiple Jewish orthodox streams, including Sephardic (North Africa lineage) and Lithuanian (East Europe lineage), such as Hassidim and Chabad Lubavitch. Serving God and following the Torah's commandments is the ultimate purpose of directing Haredi movements $[15,16]$. The ultra-orthodox approach to life highlights the importance of self-control and adherence to Kashrut (for instance, not mixing dairy and meat in the same meal), non-labor on Sabbath (Saturday), and family purity (marriage intimacy rules). Although over the last decade and a half, there has been a moderate decline in ultraorthodox fertility rates in Israel, from 7.5 live births per woman between 1998 and 2004 to 
6.6 between 2007 and 2019, it is still much higher than the fertility rate for 2018-2019 of 2.2 for secular women.

Haredi people typically reside in enclosed neighborhoods or towns that are entirely shut down on Shabbat (Saturday) and holidays regarding any sort of work. The streets are blocked for public/private transportation, and all merchandise stores are closed from Friday evening until Sunday morning. Traditionally, women focused on their home and family so that their husbands could pursue religious studies. However, as a result of poverty, women have started pursuing academic degrees with approval from community leaders (rabbis) to generate income for sustenance and livelihood purposes [17,18]. May-Yazdi and BenDavid-Hadar [19] find a linkage between income, academic education, and financial literacy among households of ultra-orthodox students compared to their counterparts. This can become leverage to decrease the community poverty rate as students gain skills to effectively manage their budget, investment, saving, and credit and debt accounts.

Several studies have discussed impediments that discourage Haredi women from applying to higher education colleges and entering the job market [20]. The obstacles are derived from many children under their supervision, financial struggle, insufficient governmental sponsorship, and scarce work offers [21]. Another matter of concern relates to the fear of weakening religious faith. While several scholars have found that higher education diminishes religious commitment-for instance, a change from conservative to liberal views [22] - others postulate contrary findings [23]. Surprisingly, evidence exists that part of the student population undergoes a strengthening of religious convictions to protect themselves [24].

These factors become later antecedents for the drop-out of students enrolling in college. According to matriculation statistics published by the Education Ministry, the rate of eligibility to graduate high school over the 2019-2020 school year stood at $83.9 \%$ in the secular community versus $24 \%$ among ultra-orthodox women. Furthermore, only $8 \%$ of the ultra-orthodox students acquire a matriculation certificate that passes the threshold for admission to a university-level institution [14]. At a pace of $4 \%$ per year, the growth rate of the ultra-orthodox community in Israel is higher than that in any western nation. Its root cause is marriage at a young age. Specifically, $56 \%$ of ultra-orthodox women marry before the age of 21 compared to $17 \%$ of secular Jews [13]. Furthermore, the Central Bureau of Statistics noticed an association between religiosity among Israeli Jews and postponing childbirth, with $36 \%$ of secular Jews having their first baby at age 30 or older compared to $8 \%$ ultra-orthodox. Consequently, approximately $60 \%$ of the ultra-orthodox community is under the age of 20 compared with $30 \%$ of the general Israeli population [14].

To amend the above-mentioned discrepancy, a government resolution to facilitate access to higher education for the Haredi population [25] signaled a change in attitude. The Israeli Council of Higher Education began instituting academization for the Haredi population by establishing designated academic programs [26]. The ultra-orthodox population responded positively, and between 2004 and 2016, ultra-orthodox enrollment increased from 600 to 11,000 students [27]. However, these remarkable figures were initially offset by the high drop-out rate of ultra-orthodox students: $41 \%$, which was almost twice the drop-out rate of general Israeli society students [28]. Jointly, these data indicate that there is growing interest among ultra-orthodox individuals to acquire higher education, but that a variety of obstacles hinder many of them from accomplishing their mission. Several studies on these questions revealed that ultra-orthodox students pursue higher education primarily for economic sustenance while striving to preserve their conservative worldview; other studies revealed fulfillment and status as antecedents [29].

For example, Dehan [30] describes an Israeli pioneer program in the discipline of social work tailored for the Haredi population. The preliminary program (1997-1999) was established by the Paul Baerwald School of Social Work of the Hebrew University of Jerusalem (PBS) in collaboration with the Haredi college for women, Neve Yerushalayim College (NYC), and the oversight of the Israeli Ministry of Social Affairs. Its success made the education institutions realize that the Haredi community can be semi-integrated into 
the mainstream education system, which is a notion that seemed unachievable until its inception as the Haredi sector's request for off-campus, non-mixed gender classrooms conflicted with the principle of non-sectarianism, which was an uncompromised value. As a result of the positive feedback from students, the Israeli council of Higher Education started approving similar endeavors, mainly in the domains of social work and instruction [31]. Similarly, Segev and Strauss [32] delineate the fruitful formation of a joint nursing program custom-tailored for Haredi women (Tessler Academic School of Nursing), which was established by the affiliation of the Ruppin Academic Center (a liberal secular institution) and the Sanz Medical Center-Laniado Hospital (founded in 1976 by the Klausenberg rabbi of the Sanz Chassidic movement and conforms to Jewish law in every detail).

In the last century, the international academic system approach has been designed to provide scholarships for minority students in higher education with a focus on ethnic, racial, and gender inclusion [33]. However, religious diversity on campus was assessed by quantitative proxies, such as minority student's GPA, instead of listening to the students' desperate need for a two-fold supportive infrastructure (academic and emotional), which would help them sustain a strong opposition within their core families for pursuing higher education; this can sometimes lead to their exclusion from friendship circles in which they were raised from childhood. Consequently, identity and value conflicts among highly religious students were neglected, although psycho-social adjustment stimulates academic success and well-being in college.

Ultra-orthodox students who hail from religious communities, in which university institutions are distrusted, are commonly first-generation higher education students, which is a status demanding a high level of adjustment and creating a dual identity. Firstgeneration students who break away from family traditions can face condemnation from their home communities [34], further complicating their adjustment to college. As a simple example, such students are likely to struggle finding an arranged marriage after graduation due to the way the matching criteria within their religious society has been built for generations around stereotypes, which rank people who are attempting to derail from their community path charted by rabbis poorly. These long-term life-changing benefits derived from career-related freedom of choice were coupled with dilemmas documented in the literature, including the following: self-identity crisis; decline in faith; breaking ties with family and friends, and fear of getting stuck in the middle; neither being accepted by the secular community to find a satisfying job opportunity nor being able to fit back into the religious community thread after being exposed to non-religious contents and temptations. For instance, Barth and Ben-Ari [35] shed light on the isolation ultra-orthodox women whose marriage results in divorce are subjected to. Overall, the goal-oriented ultraorthodox students were anxious that their community leadership can order their secretive expulsion from religious circles (prayer group, arranged marriage, etc.) by forbidding or limiting contact with them, out of fear their conventions cause rabbis to lose control over members of society by diffusing liberal norms of behavior within the community.

\section{Methodology}

\subsection{Data Analysis Method}

Data were collected in two complementary methodologies: quantitative surveys and a case study. In the beginning, to better understand the arena of an orthodox campus, an interview was conducted with the chief director of Tmura Seminary, which is affiliated with the Azrieli College of Engineering and is associated with its ultra-orthodox branch. The interview protocol with the director of Tmura Seminary is described in Appendix A. In the interviews, the director was asked to share information about motivations for pursuing these degrees, as well as their concerns about challenges in and reflections on the process of building, for example, unique educational enterprises catering to ultra-orthodox women.

The interview provides the foundation to build a case study approach, which is appropriate due to the unique nature of the orthodox colleges. In addition, this approach supports our interest in building theoretical and managerial insights on the topic of ultra- 
orthodox college institutions, which has had little coverage in the literature [36]. Table 1 summarizes information about Tmura Seminary.

Table 1. Summary information about Tmura Seminary.

\begin{tabular}{|c|c|}
\hline Year of Establishment & 2012 \\
\hline Degrees offered & $\begin{array}{l}\text { Industrial engineering, } \\
\text { Software engineering }\end{array}$ \\
\hline Students' population composition & Ultra-orthodox women \\
\hline Preparatory program & Six months \\
\hline Various types of entry admissible & $\begin{array}{l}\text { High school matriculation certificate or } \\
\text { SAT exam }\end{array}$ \\
\hline Years of study to graduate & 4 \\
\hline Diversity of curriculum & Judaic and Torah (Bible studies) \\
\hline Job placement of alumni & $\begin{array}{l}\text { Intel, Mobileye, Cisco, } \\
\text { government agencies, etc. }\end{array}$ \\
\hline Location & Har Hotzvim, Jerusalem \\
\hline Dormitory & Not available \\
\hline Full online program & No, some classes are online \\
\hline English language classes & No, classes are in Hebrew \\
\hline Number of students & 20 (per year, cohort) \\
\hline Grant funding sources for students & $\begin{array}{c}\text { Scholarships } \\
\text { (Kemach and Toronto) }\end{array}$ \\
\hline Tuition fee cost & $\begin{array}{l}\text { Israel government standard academic } \\
\text { university fee }\end{array}$ \\
\hline Academic accreditation & $\begin{array}{c}\text { Certified by the Israeli Council of } \\
\text { Higher Education }\end{array}$ \\
\hline Level of diploma & Undergraduate \\
\hline
\end{tabular}

Afterwards, data were collected using a Google survey. Statistical analysis was performed using SPSS software. We chose to conduct chi-square analysis to compare Tmura Seminary and Azrieli general colleges, as this is an appropriate method to test statistical independence between two categorical variables. The data were collected by administering anonymous questionnaires to female students from all age groups and levels (freshman, sophomore, junior, and senior) who were studying industrial and software engineering during the fall semester of 2020.

\subsection{Sample Data Collection}

The case study data collection started in 2019. It spanned over one year of investigation and encompassed students at all levels (freshman, sophomore, junior, and senior). The half-year preparatory program was not included in the sample, as its students were located at a satellite campus.

Azrieli College of Engineering, located in Israel, was selected as the subject matter bedrock for investigation. It has both women-only ultra-orthodox programs and general admission secular programs open to all students, enabling the comparison of the two types. The fact that it is an Israeli public institution that trains engineers fits the research focus on STEM. It provides access for first-generation students to higher education and is committed to building systems of equity in order to remove bias from the academic arena. This vision energizes the close-knit relationship between students, faculty, staff, alumni, partners, and the community. It is located in the Ramat Beit HaKerem neighborhood of Jerusalem, between Jerusalem's two major high-tech industrial areas, Har Hotzvim and the 
Jerusalem Technology Park, which are in need of fresh alumni equipped with engineering 21st century business analytics and big data skills. To fulfill that need, Azrieli College of Engineering Jerusalem offers undergraduate (Bachelor of Science, B.Sc.) degrees in software engineering, industrial management, electrical engineering, advanced materials engineers, pharmaceutical engineering (cooperation with TEVA), and mechanical engineering, as well as postgraduate (Master of Science, M.Sc.) degrees in software engineering and entrepreneurship. The college also offers a pre-academic gap-year program to increase diversity by enabling students with weak high school backgrounds to strengthen skills in order to be admitted and succeed in the college's engineering departments.

A questionnaire was sent to Tmura Seminary students studying industrial and software engineering. It is important to note that Tmura Seminary admits only ultra-orthodox Jewish women students (male students are not admitted). A similar questionnaire was administered to the secular Azrieli general college targeting non-orthodox female students from industrial engineering and software engineering departments. The general college of Azrieli admits men too, but they did not receive the questionnaire. The questionnaire was composed of numerous independent faculty members to ensure content validity. It was administered using a Google questionnaire prepared by an undergraduate student as part of her compulsory graduation term project. To encourage students to fill out the questionnaire, follow-up email reminders were sent to students by the head of Tmura Seminary and senior instructors in Azrieli College. The sample was composed of 143 students: 70 from Azrieli and 73 from Tmura. The response rate was approximately $90 \%$ in Tmura Seminary and $75 \%$ in Azrieli. Appendix B describes the questionnaire items.

\section{Statistical Results and Findings}

\subsection{Students' Sources of Information about College Enrollment Opportunities}

For many ultra-orthodox students who received little or no exposure to the outside world, such as external media outlets (TV, radio, etc.), and are filtered or entirely blocked by their community since childhood to prevent non-conforming behavior, enrolling in college signifies a milestone to adulthood, where they are confronted with debates about their real purpose in life, which has the potential to become a turning point in their faith development [37]. As an illustrative example, it is common practice for people belonging to an ultra-orthodox community to own a kosher phone, a cellular device with limited internet access in order to avoid Bitul Torah-the negligence of Bible study [38]. In 2005, the leaders of Israel's ultra-orthodox community began a campaign to replace commercial mobile phones with kosher cell phones, which can be used to make and receive calls but have no other capabilities. Much of the campaign was conducted on walls and notice boards through Pashkevilim (wall posters) medium, which is an unofficial channel of communication popular in the Haredi community [39]. Their community has separate newspapers in which photos are screened for adherence to modesty rules. The impact of academic knowledge on religious beliefs has been examined in the literature. Similarly, the libraries in the ultra-orthodox community block internet connection and forbid offering liberal content that secular public library archives commonly hold [40]. The statistical analysis indicated a clear difference between the two groups in the category of friends (Figure 1). In fact, in the category of friends, as a source of information about the college, there is a ratio of 2:1 in favor of Tmura (ultra-orthodox). In contrast, in the category of public advertisement as a source of information about the college, the outcome is the opposite, 1:2, in favor of Azrieli (secular). The logic can explain that the orthodox society blocks information from outside sources to reduce the potential stream of non-orthodox content or the influence on the community members; therefore, the remaining source of information becomes friends. In contrast, in secular society, the main source of information is public media advertisement. The chi-square test shows a dependency between college type and source of information (chi-square value $=12.51$; significant $p$-value $=0.006$ ). The statistical difference was evident when conducting a pairwise chi-square test between college type and friends (chi-square value $=12.21$; significant $p$-value $<0.001$ ). 


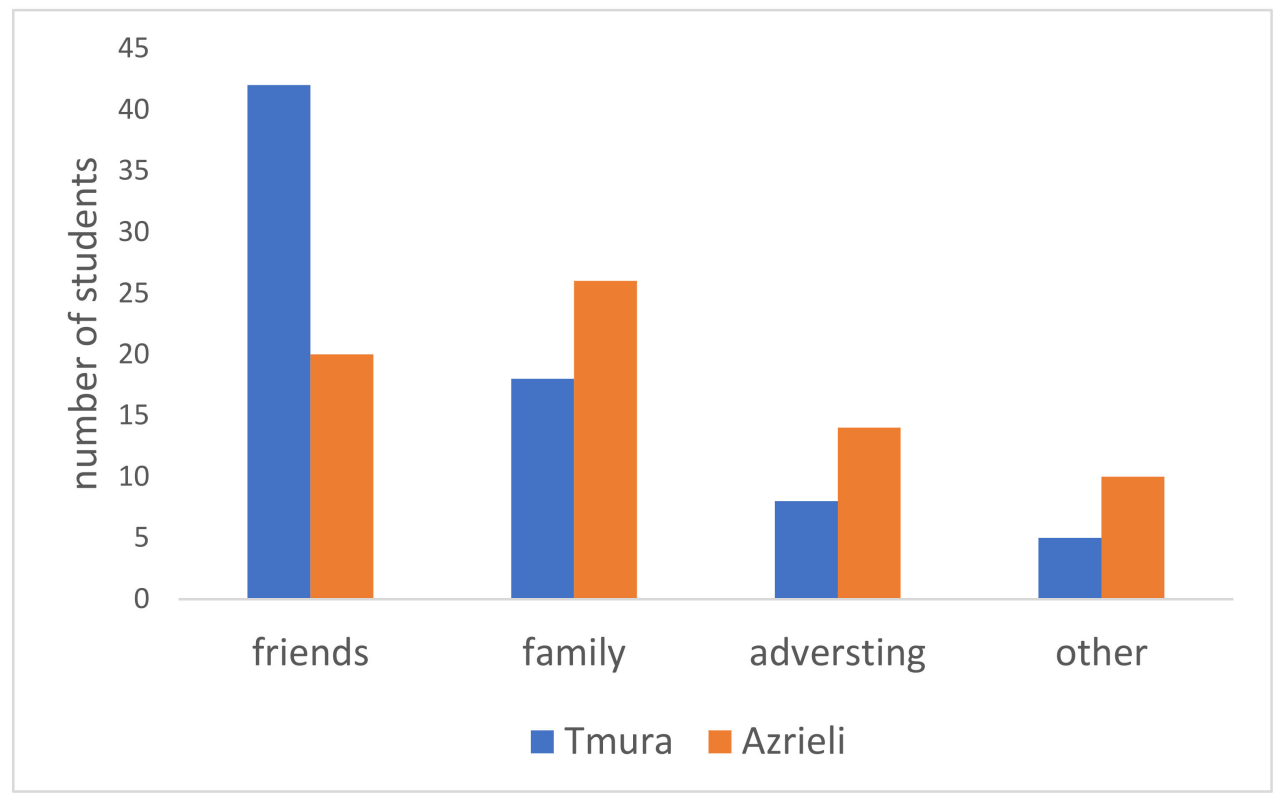

Figure 1. Source of information about college (Tmura vs. Azrieli).

To fine-grain the distribution of the source for information within Tmura college, Figure 2 was constructed. It elucidates a significant difference among sources of information for prospective students about Tmura within the ultra-orthodox community (chi-square $=46.29 ; p$-value $<0.001$ ), where friends account for $57.5 \%$ of the sources, while advertisement accounts for merely $11 \%$.

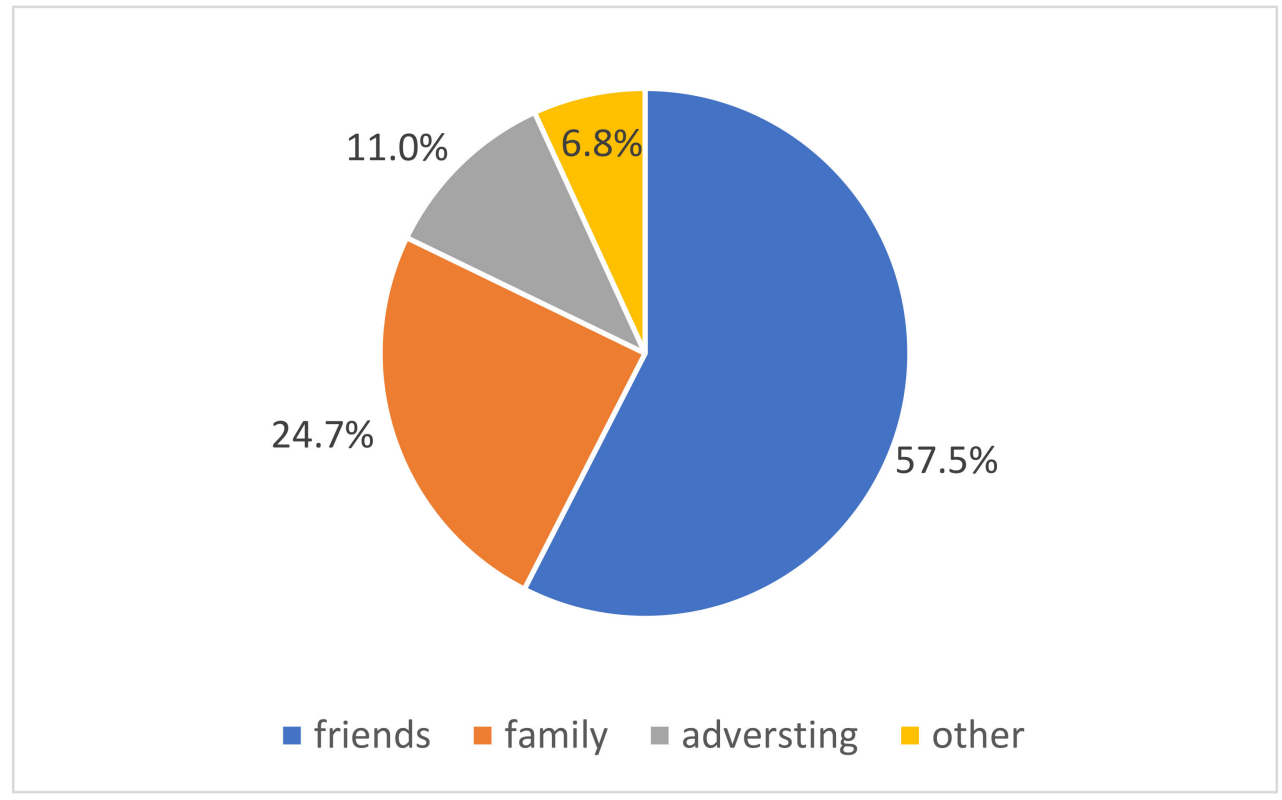

Figure 2. Source of information about college within ultra-orthodox community.

\subsection{Factors Influencing Students to Pursue STEM Degrees at College}

There is a clear difference between the two colleges regarding the impact of livelihood as a motivating factor to enroll in college. For most of the students in Tmura (69/73), livelihood is important. The ultra-orthodox women enroll in studies to learn a practical profession that leads to job placement and can ultimately put food on the table for their families, which are in dire need of income since they are the main providers within the family. At the same time, husbands devote most of their day to Limudei Kodesh (learning a variety of sacred Judaic texts, such as Talmud, consisting of Gemara and Mishnah). The 
chi-square test shows a dependency between college type and livelihood as a motivator (chi-square value $=3.99$; significant $p$-value $=0.046$ ).

Interestingly, there is a clear difference between the two colleges in networking as a motivating factor to enroll in college. The ratio in Azrieli (secular) compared to Tmura (ultra-orthodox) is 2:1 in favor of meeting new colleagues on campus. In contrast, the ultra-orthodox community is close-knit in nature, where new acquaintances are created mainly through relatives and friend networks. The chi-square test shows a dependency between college type and networking as a motivator (chi-square value $=6.57$; significant $p$-value $=0.010$ ).

To fine-grain the distribution of motivating factors to enroll in college within the ultra-orthodox Tmura Seminary, Figure 3 was constructed. It elucidates insights consistent with the theory, showing that livelihood is marked by $94 \%$ of responses, career by $87 \%$ of students, and opportunity to get to know people by $19 \%$ of responses within Tmura.

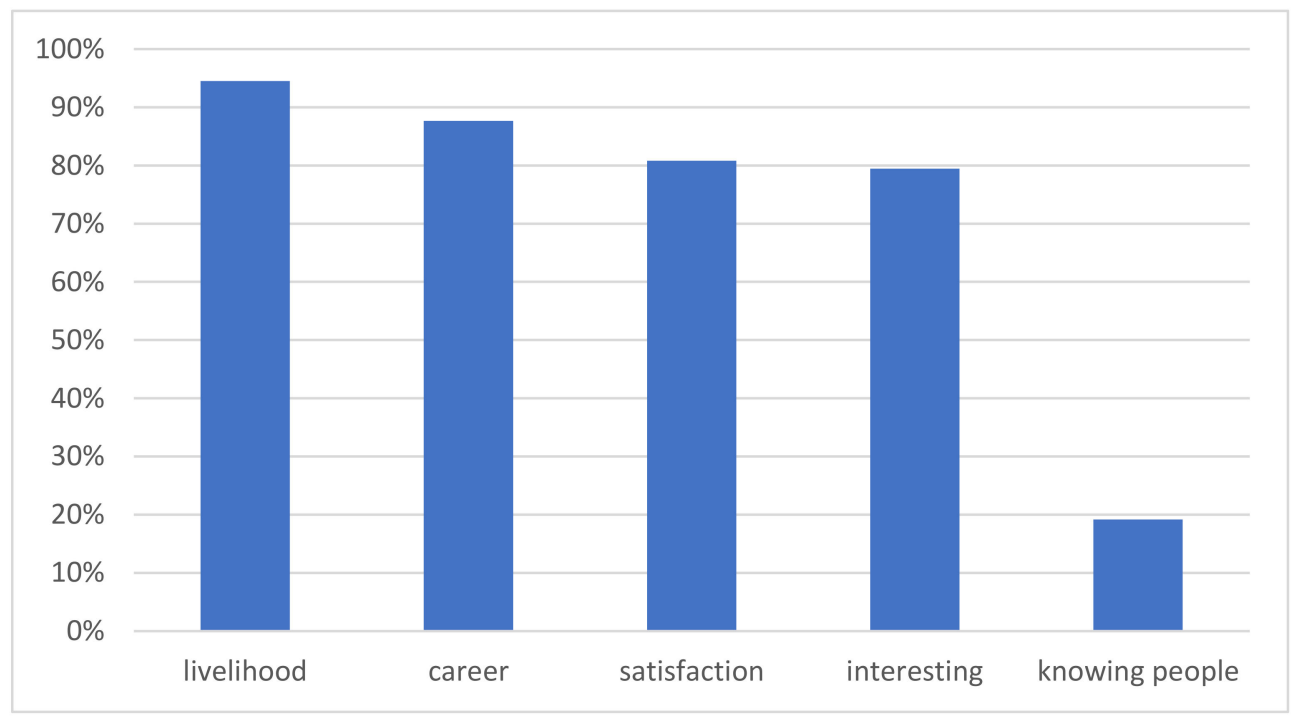

Figure 3. Antecedents to study STEM among ultra-orthodox students.

\subsection{Women as Role Models of Senior Faculties}

There is a clear difference between the two colleges in female instructors serving as successful faculty members. While in the secular college, Azrieli, $48 \%$ of students highly regard a woman lecturer as a role model. In the ultra-orthodox seminary, Tmura, this factor is reduced to $24 \%$. In Tmura, the lecturers serve less like a role model for the students as in the ultra-orthodox community, the rabbi (male Jewish sage) is the port of call for guidance in any matter. It is essential to realize that the leadership position of rabbis extends far beyond biblical rules to daily decision-making in mundane affairs. In contrast, in the secular community in Israel, women are more feminist in character and, therefore, tend to admire female instructors who managed to reach highly ranked positions as professors by acquiring a Ph.D. degree. The chi-square test shows a dependency between college type and instructor capability to become a role model in students' eyes (chi-square value $=7.79$; significant $p$-value $=0.005$ ).

\subsection{Students' Employment While Pursuing a College Degree}

There is a clear difference between the two colleges' employment statistics during the period of study toward a degree. While in the secular college, Azrieli, $49 \%$ of students work during the study period, in ultra-orthodox Tmura Seminary, this factor reduces to $30 \%$. Several factors contribute to this discrepancy. For example, in Tmura, many ultra-orthodox students got married in their early 20s and are responsible for raising children, which makes work and study highly strenuous. In contrast, in Azrieli, many students are single and in their mid-20s, and they need to have at least a part-time job in order to cover their 
living expenses. Additionally, the ultra-orthodox community limits the ability to work in student-related jobs from the outset due to religious restrictions [5]. In sum, many jobs are regarded as inappropriate in terms of modesty (mixed environments between men and women). Consequently, students in Tmura seminary are in dire need of a scholarship to fund their studies. The chi-square test shows a dependency between college type and employment (chi-square value $=21.12$; significant $p$-value $<0.001$ ).

\subsection{Root Causes of Drop-Out from College}

Surprisingly, the overall rate of drop-out from freshman until senior year differs sharply between colleges (Azrieli $=10 \%$, Tmura $=3 \%$ ) in favor of Tmura. Ben-David Kolikant and Genut [41] find that prior education, in the Jewish script titled Talmud, enhances competency in number representation among computer science students in digital logic courses, corroborating the unique virtues stemming from the ultra-orthodox education style that needs to be leveraged as a springboard for integrating Haredi students into academia. Interestingly, the Jewish practice of studying in Chavruta (a method used by Talmud exploration in which a pair of pupils engage in a lively learning debate called pilpul in Hebrew) gained momentum in South Korea a way to inspire creativity among schoolteachers.

The students in the ultra-orthodox Tmura Seminary were asked for their opinion on antecedents for drop-out from college. In order to fine-grain the antecedents, Figure 4 was constructed. It elucidates a significance difference among sources of drop-out within an ultra-orthodox community (chi-square $=72.73$; $p$-value $<0.001$ ). Difficulty in studies accounts for $64 \%$ of the antecedents for drop-out. This phenomenon stems from the poor preparation that ultra-orthodox students arrive at college.

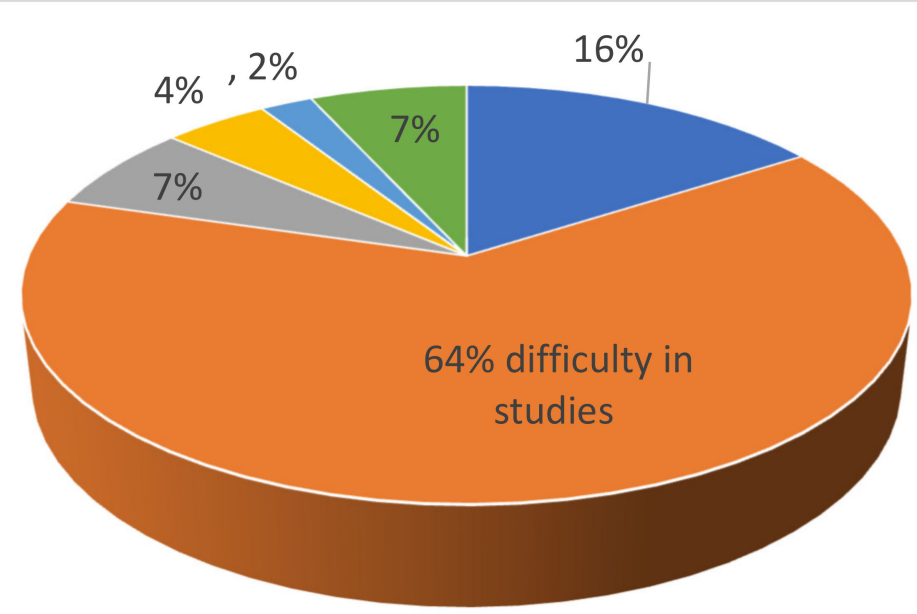

$$
\begin{array}{ll}
\text { - discrepancy } & \text { - difficulty in studies } \\
\text { - economic difficulty } & \text { - family }
\end{array}
$$$$
\text { - overload / pressure }
$$$$
\text { - distance from campus }
$$

Figure 4. Antecedents for drop-out from college among ultra-orthodox students.

\subsection{Students' Life Priorities}

There is a clear difference between the two colleges in the importance of family in students' eyes. In the ultra-orthodox Tmura Seminary, this factor is $100 \%$ important, while in the secular college, Azrieli, it is $94 \%$. Several factors contribute to this discrepancy. In the ultra-orthodox community, establishing a family is regarded as the highest priority in life. People who are not married are regarded as unsuccessful in accomplishing life's purpose. The chi-square test shows a dependency between college type and family value (chi-square value $=4.29$; significant $p$-value $=0.04$ )

Additionally, there is a clear difference in the importance of a career in students' eyes. In the ultra-orthodox Tmura Seminary, this factor is $76 \%$ important, while in the 
secular college, Azrieli, it is $97 \%$. Several factors contribute to this discrepancy. In the ultra-orthodox community, the career is traditionally less relevant than establishing a family and educating children to follow the rules of the Bible. In contrast, the secular community encourages women to develop a successful career as part of a feminist perspective on life. Moreover, women are encouraged to take over jobs traditionally occupied in secular society by men in the past. The chi-square test shows a dependency between college type and career value (chi-square value $=12.95$; significant $p$-value $<0.001$ )

In addition, there is a clear difference between the two colleges in the importance of spirituality in students' eyes. In the ultra-orthodox Tmura Seminary, this factor is $98 \%$ important, while in the secular college, Azrieli, it is $68 \%$. Several factors contribute to this discrepancy. In the ultra-orthodox community, spirituality is instilled into children from a young age through rigorous Judaic studies in Ulpana (women's ultra-orthodox school). Knowledge of Torah rules and commentaries is assigned an esteemed value in the community, which improves the chances of finding a prestigious companion for an arranged marriage. In the secular community, spirituality is studied for a few hours in school programs, and exams on its content are not rigorous. The chi-square test shows a dependency between college type and spirituality value (chi-square value $=23.92$; significant $p$-value $<0.001)$.

\subsection{Enrollment in Preparatory Program (Mechina) Prior to Freshman Year}

There is a clear difference between the two programs in preparatory studies. In the ultra-orthodox Tmura Seminary, 64\% of students are enrolled in Mechina, whereas in the secular college, Azrieli, the enrollment level is $40 \%$. Several factors contribute to this discrepancy. In the ultra-orthodox community, education is geared toward learning Biblerelated topics. Consequently, ultra-orthodox students admitted to college start from a low level and required further preparation before beginning degree courses. The chi-square test result supports a dependency between college type and Mechina enrollment (chi-square value $=8.52$; significant $p$-value $<0.001$.

\subsection{Scholarship Funding}

To a large extent, students in Israel are dependent on funding, as secular women enroll after completing high school for a compulsory period of two years in the Israel Defense Forces without financial compensation, while the ultra-orthodox students come from poor communities. Consequently, in the ultra-orthodox Tmura Seminary, $82 \%$ of students receive scholarships, whereas, in the secular college, Azrieli, the level of scholarship acceptance is $54 \%$. The ultra-orthodox students need scholarships, as neither their spouses work, making the scholarship a survival necessity for the household. The chi-square test result supports a dependency between college type and scholarship acceptance (chi-square value $=8.52$; significant $p$-value $=0.004)$.

\subsection{Students' Matriculation Exams in Mathematics, Physics, English, and Computer Science}

There is a clear difference between the two colleges in taking matriculation exams in mathematics at high schools (Ulpanot-for ultra-orthodox students). It should be noted that the Szold Institute administers ultra-orthodox students an alternative matriculation test. In the ultra-orthodox Tmura Seminary, 59\% of students took the Szold test in mathematics, while in the secular college, Azrieli, 93\% of students took a matriculation exam in mathematics. In the secular community, mathematics is highly regarded as a skill necessary to succeed in life, whereas it is a tool for financial transactions in the ultra-orthodox community. The chi-square test shows a dependency between college type and mathematical training (chi-square value $=22.29$; significant $p$-value $<0.001$ ).

Similarly, the two colleges differ in learning for matriculation exams in physics before coming to college. In Tmura, 1\% of students took a Szold test in physics, while in Azrieli, $21 \%$ of students administered a matriculation exam in physics. The chi-square test shows a 
dependency between college type and physics training (chi-square value = 14.47; significant $p$-value $<0.001)$

Finally, there is also a clear difference between the two colleges in English proficiency. In the ultra-orthodox Tmura Seminary, 56\% of students took a Szold test in English, while in the secular college, Azrieli, 97\% of students were administered a matriculation exam in English. In the secular community, English is highly regarded as a way to communicate with the global world, whereas in the ultra-orthodox community, English is associated with a foreign culture, which may expose students to non-Jewish content; therefore, in many Haredi households, a TV is a non-existent device. The chi-square test shows a dependency between college type and English studies (chi-square value $=33.11$; significant $p$-value $<0.001)$. This result is not surprising when considering that in several ultraorthodox enclaves within Jerusalem, the dominant language is Yiddish (German dialect encompassing components of Hebrew, Aramaic, etc.), used at home, schools, and in daily merchandise transactions. According to Assouline and Dori-Hacohen [42], the Yiddish language reflects a unifying membership ideology assigned symbolic value to maintain community boundaries. It is prioritized in the ultra-orthodox education system over modern Hebrew from childhood.

There was no significant difference between colleges in computer science, as the ultraorthodox community realizes that knowledge of information systems and computers is essential in the 21st century. Furthermore, rabbis have instructed community members to install software blockers (labeled as kosher devices), which enable usage while filtering internet access. Web admins create designated portals, such as Koogle (a kosher search engine) with screened content, vetted user forums, and control over public discussion [43].

\subsection{Post-Graduation Avenues of Ultra-Orthodox Students}

Students' plans after graduation are indeed an interesting avenue for exploration. Figure 5 shows the distribution of students' responses. Interesting jobs (43\%), a successful career $(28 \%)$, and a good salary $(13 \%)$ were dominant replies. The ultra-orthodox students showed little interest in pursuing a Masters-level degree. Schupak [44] attributed this result to the stereotyping and bias ultra-orthodox faculties encounter in academia. This provides evidence that Tmura students' prime goal is to seek a way to provide for their families.

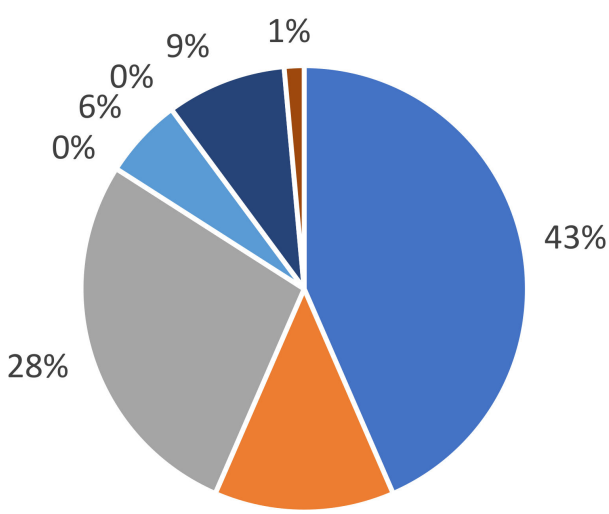

$13 \%$

$$
\begin{aligned}
& \text { - interesting job good salary a amazing career } \quad \text { job and family }
\end{aligned}
$$

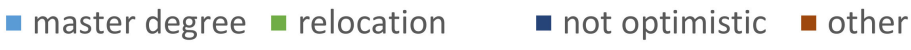

Figure 5. Post-graduation intentions of ultra-orthodox students.

\section{Discussion}

The director of Tmura introduced the seminary by explaining the opportunity Tmura gives for orthodox women to learn engineering at a high level: 
"Tmura opened as the result of the growing demand for adapted study environment towards ultra-orthodox women. Although ultra-orthodox women were already integrated into low-tech domains such as quality assurance, Seminary Tmura opened the door to advanced high-tech disciplines. As part of their integration into the industry, the students receive professional and practical workshops and personal counseling to prepare them to the industrial arena and deal with the vast array of jobs. Among the companies that employ the graduates of the Tmura are prestigious Israeli conglomerates such as El Al department of aircraft control systems, Mobileye in the development of technology for autonomous cars, Cisco, Israel Aviation Industry, etc. The graduates earn high-paid salaries that fit the high-tech world with a work environment suitable for ultra-orthodox women.

The curriculum is completely adapted to the Jewish core values based on the guidance of an educator (rabbi), religious studies, [and] Halacha (Jewish faith) leading women to the establishment of a home grounded in Torah (Bible) foundation, along with a bachelor's degree in engineering. In addition, Tmura seminary and Azrieli College work together to build a network [that] integrates the women in the prestigious high-tech industries through collaborations and connections that the alumni have also created and their good names that [go] before them".

In 2018, Tmura Seminary inaugurated a new campus with renovated classrooms and state-of-the-art computer labs. On the campus, more than 100 young women are studying. Tmura has existed since 2011, but until 2018, the students had one major to specialize in: software engineering. Hence from 2018 hence, they can also learn industrial engineering with an information system specialty.

Director of Tmura elaborated:

"Indeed, graduates finish the program with [an] engineering degree from Azrieli college of engineering, which is widely recognized in Jerusalem and across Israel. The admission requirements to be accepted into the program are the same as Azrieli college, so most women need to learn in [a] preparatory program (mechina) or preparatory courses to compensate for the lack of scientific subjects. They usually take soft exams during this preparatory program that last half a year (40 ha week).

After completing the mechina, they can choose between industrial engineering and software engineering. There are about 20 students in each degree every year. While asked why there are only two options for [the] degree, the director explained that other degrees such as electrical engineering have a masculine image in the ultra-orthodox community. In contrast, those two tracks are acceptable for women".

The campus is located in the Har HaZofim neighborhood in Jerusalem, where most of the high-tech enterprises in Jerusalem are located. On the Beit Adar campus, women learn in renovated classrooms, practice computer courses in well-equipped computer labs, and have their kitchen, which can be used at any time to cook kosher food. There is no dormitory on campus.

Beyond the academic courses that Azrieli College's esteemed teachers provide, women in Tmura Seminary enjoy extended extracurricular activities, such as religious learning and tours all over Israel. The director quoted one of the lecturers that describes

"The cohort of students is organized as a unified learning group in opposition to individual students that are frequently encountered in other colleges, and it's probably the most important factor contributing to the ultra-orthodox women success during their journey".

The second factor in the interview is the educational support they receive from the administrative staff, i.e., help in every problem encountered during their studies (the staff directly speak with the teachers to help solve problems). Specifically:

"There are private tutoring teachers for students that gave birth and have babies at home".

To help graduates find a job, the seminary organizes several workshops, such as how to write a curriculum vitae or job interview practice. Another helpful resource is 
cooperation with start-ups through internships. As a result, according to the director of Tmura Seminary,

"Graduates find jobs on average nine months after graduation".

The director provided additional statistical data:

"For example, $80 \%$ of women just finished high school, 15\% are in professional reconversion, and the last 5\% are women who start learning later. In terms of location, about $60 \%$ are from Jerusalem, 25\% [are] from cities around Jerusalem such as Bet Shemesh or Beitar, and 15\% come from the north, south, and center of Israel (because Tmura has competitors in these regions)".

The program length of studies extends to approximately 4-5 years (including a 6-month preparatory program), composed of 2.5 years of regular morning studies and 1.5 years of evening studies. This allows students to start working during their studies; indeed, approximately $50 \%$ of them do so. According to the director:

"Seminary Tmura gives a chance to the students to start building their resume already while studying and helps them to finance their studies." She also explained, "Most of the students receive scholarships from Keren Kemach for ultra-orthodox students (about 70\% of tuition costs), and more scholarships such as subsistence scholarships are available to apply. The tuition cost at seminary Tmura is equivalent to Israel public university tuition costs based on the council of higher education framework.

Alumni integrate into prestigious high-tech companies such as Intel, Mobileye (about 30 alumni are working there today), and Cinamedia. Another major place for employment is government agencies since Jerusalem is the capital of Israel, where most ministry offices are based.

The women expressed notable challenges such as study overload (caused by inadequate English proficiency and poor mathematical background) challenging to balance with family and kids. For example, having classes on Friday morning can be of particular challenge for an ultra-orthodox woman who needs to cook meals for Shabbat (or high holidays) and has to halt all activities in the afternoon before Shabbat enters. Interestingly, the quarantine period of COVID-19 in which the college transferred to online paradigm proved to be convenient for the ultra-orthodox track, and it is going to be partly continued after the pandemic is over".

The establishment of colleges for women creates inclusive higher education environments where everybody in society is supported to reach their full potential and succeed [45]. The importance of creating job opportunities for ultra-orthodox women stems from a recent report from the Israel Democracy Institute [14], which finds that household income for ultra-orthodox families is 58\% lower than that for other Jewish Israeli households. Over the last five years, there was a 33\% increase in the number of male students devoting most of their workday to Limudei Kodesh (religious studies) in Israel, further underlining the responsibility of women as breadwinners. In the last decade, a rise in the percentage of ultra-orthodox girls taking Bagrut (matriculation exams) from 31\% to 55\% was recorded, compared to a decline in the parallel rate among ultra-orthodox boys (from 16\% to 13\%).

An analysis of the qualitative interviews elicited various antecedents for deciding to acquire an academic diploma (most participants noted more than one), which may be classified into three categories: breaking the community's societal boundaries and building connections with the outside world; unlocking the potential for self-fulfillment as an ultraorthodox woman; and earning a living as the sole provider to escape the poverty circle since the husband is unemployed.

In order to adhere to the restrictions of the interaction between genders set by ultraorthodox rabbis, a women-only college institution was established. This is a logical choice as it creates a safe environment for ultra-orthodox students given the prejudice posed if they studied at a university open to everyone. Bowman and Smedley [46] discovered evidence that satisfaction from college experience decreases when the social status of the 
students' religion is low. Extremely religiously committed students to tend to have a negative experience at college compared to those who are less religiously strict [47]. This may be exacerbated when religious identity is shown through women dressing to adhere to modesty rules (Tzniut in Hebrew), such as wig-wearing [48]. Having a women-only orthodox college program helped to mitigate concerns by decreasing fears of alienation, prejudice, or discrimination. Similarly, socializing with students with similar religious principles was positively correlated with increased religious commitment and overall satisfaction [49].

Overall, this study revealed an impression of the ultra-orthodox community being a more versatile [50] and open-minded group than occasionally portrayed by the media [51], allowing students to adopt knowledge on technology, such as the Internet, introduced across the curriculum without disrupting religious core values and ideologies. It seems that the walls in Israeli society are not as high as assumed in the past [52].

\section{Conclusions}

Ultraorthodox and secular groups can feel uncomfortable in the presence of each other, as their lifestyle reflects neither secularity nor spirituality but a free choice of behavior or religious devoutness to conduct their life. A simple example is the requirement of ultra-orthodox students to dress modestly on campus and not contact the opposite gender for neither mundane matters nor study circles, which secular students regard as an unacceptable demand. This leads to the need to establish a women-only institution for ultra-orthodox students where everybody has a similar dress code and rituals.

This study is one of the first of its kind to analyze a unique group of minority students, ultra-orthodox women from the Haredi community in Jerusalem, Israel, who are embarking on a journey to gain an academic diploma specifically in STEM. Most previous studies have focused on social work disciplines as most ultra-orthodox women study tax accounting, graphic design, and social sciences, emphasizing becoming educators in religious teaching institutions [53].

An insight emerging from the study is the ability of ultra-orthodox students to graduate successfully with a low drop-out rate. Notably, the students were able to find a rewarding job, proving their hard work was justified and setting a positive role model for followers. This accomplishment should not be taken for granted, as the high-tech market in Israel is competitive with a clear preference to hire alumni from the Israel Defense Forces prestige technological units, which is an experience that the ultra-orthodox students are unable to highlight in their curriculum vitae, as many were lawfully exempted from service due to their religious/marital status.

Two fruitful avenues exist for future research. First, whether the results achieved in this study apply to ultra-orthodox Jewish women outside Israel should be assessed. For example, Longman [54] attempted to address this question through an investigation conducted inside the Orthodox Jewish community of Antwerp, Belgium. This fascinating topic should be examined subtly, as the Jewish communities worldwide are composed of multiple streams. For example, in the United States of America, there is a wide religious spectrum of Jewish denominations (reform, conservative, reconstructionist, and orthodox), each deserving equal research attention, which autoethnography methodologies might be able to discern. A second fruitful avenue for future research would be to compare whether the results obtained here apply to women-only colleges affiliated with different religions and residing in various national cultures. It would be interesting to compare the students' demographic data (age, marriage status, etc.), whether they encounter similar community pressure, have a lack of STEM background if they struggle to find a job upon graduation, and how the institutions from various religions manage to bridge these gaps. Supporting the approach to tailor a unique curriculum for ultra-orthodox students, several studies have found that women differ from men in their learning process of STEM professions [55]. For instance, in the United States of America in Saint Paul, Minnesota, resides the private Catholic St. Catherine University, with the largest undergraduate Catholic women college in 
the nation, which is nurtured by the values derived from the covenant, Sisters of St. Joseph of Carondelet, St. Paul Province. It launched the National Center for STEM Elementary Education (NCSEE) and was the pioneer college in America to (a) require that all elementary education majors complete a STEM certificate program to receive a teaching license and (b) develop an engineering course specifically for elementary education majors. The certificate in STEM includes 12 credits that can be completed in less than a year, covering an advanced, wide-ranging in-class and online scientific curriculum for the K-12 classroom, such as computational thinking and coding, earth science, basic engineering, system integration, and alternative energy [56]. Such programs pave the way to improve female students' attitudes toward STEM and encourage them to elect advanced STEM courses in their careers.

Author Contributions: Conceptualization, M.N.; data curation, J.B.; formal analysis, P.D.; investigation, M.N.; methodology, J.B.; project administration, G.D.P.; resources, G.D.P.; supervision, G.D.P.; validation, A.K.; visualization, P.D.; writing—original draft, M.N.; writing—review and editing, A.K. All authors have read and agreed to the published version of the manuscript.

Funding: This research received no external funding.

Institutional Review Board Statement: Not applicable.

Informed Consent Statement: Not applicable.

Data Availability Statement: The study didn't analyze or report any data or used public dataset.

Acknowledgments: The authors would like to thank Dina Weiss from Tmura Seminary.

Conflicts of Interest: The authors declare no conflict of interest.

\section{Appendix A. Interview Questionnaire Used to Collect Data from Director of Tmura Seminary}

1. Who heads the program?

2. What are the requirements to be accepted into the program?

3. In which parts of Israel do students come from? Are there international students?

4. What degrees are proposed? Why those?

5. Are there an offering of Bible (Midrasha) studies?

6. Where is the campus situated?

7. Is there a prerequisite preparatory program (Mechina)? Is there a mentoring service for struggling students (tutoring)?

8. What age groups are the enrolled students?

9. How does the program support minorities?

10. What is the degree's duration?

11. What is the tuition fee? Are scholarships available?

12. How many students enroll each year?

13. What is the drop-out rate? In which year does it occur?

14. How does the program help the students find jobs after they graduate?

15. In which companies are alumni hired?

16. How long on average after they graduate do students find a job?

17. How does the program support women on maternity or with babies?

18. Is there a dormitory? Does a kitchen for kosher food cooking exist?

\section{Appendix B. Google Questionnaire Distributed to Students of Ultra-Orthodox Tmura Seminary and the Secular College of Azrieli}

1. On which campus do you study? (Azrieli-Bet hakerem or Tmura-Har HaZofim)

2. What was the primary source of information you heard about the college? (Friend, family, advertising, other) 
3. What influenced you to study engineering in this college? (Livelihood, career, the feeling of self-accomplishment, interesting studies, getting to know interesting people, way to pass the free time)

4. In which year of study are you? (Preparatory program, freshman, sophomore, junior, or senior)

5. Do college lecturers (women) serve as role models for you?

6. Do you know female students who drop out of studies and why?

7. Do you work while studying?

8. Do you work part or full time in a field related to your studies?

9. Please rate the importance of the following topics in your life: Marriage and having family, career, friends, spirituality, or materialism.

10. How much are the studies challenging for you?

11. Before your first year, did you enroll in a preparatory program (Mechina)? Did the college provide you during study some sort of aid such as scholarships funding, tutoring mentorship, or guidance in finding a job?

12. Did you learn these fields in high school toward a matriculation exam: Mathematics, Physics, English, or software programming?

13. Did someone in your family learn engineering?

14. Are you planning to apply for a Master's degree after graduation?

15. How do you predict your professional development in the future?

\section{References}

1. Alkaher, I.; Goldman, D.; Sagy, G. Culturally Based Education for Sustainability—Insights from a Pioneering Ultraorthodox City in Israel. Sustainability 2018, 10, 3721. [CrossRef]

2. Mooney, M. Religion, College Grades, and Satisfaction among Students at Elite Colleges and Universities. Sociol. Relig. 2010, 71, 197-215. [CrossRef]

3. Pascarella, E.T.; Terenzini, P.T. How College Affects Students: A Third Decade of Research. In The Jossey-Bass Higher and Adult Education Series; Jossey Bass: San Francisco, CA, USA, 2011.

4. Israel Innovation Authority. Israel Innovation Authority 2021 Report. Available online: https://innovationisrael.org.il (accessed on 1 January 2022).

5. Kalagy, T. Enclave in Transition: Ways of Coping of Academics from Ultra-Orthodox (Haredim) Minority Group with Challenges of Integration into the Workforce. Int. J. Environ. Res. Public Health 2020, 17, 2373. [CrossRef]

6. Golan, O.; Fehl, E. Legitimizing academic knowledge in religious bounded communities: Jewish ultra-orthodox students in Israeli higher education. Int. J. Educ. Res. 2020, 102, 101609. [CrossRef]

7. Tishby, N. Israel: A Simple Guide to the Most Misunderstood Country on Earth; Simon and Schuster: New York, NY, USA, 2021.

8. Regev, E. Challenges in the Integration of Haredi Jews into Academic Studies. In Report on the State of the Nation: Society, Economy and Policy; The Taub Center for Research in Social Policy in Israel: Jerusalem, Israel, 2016. (In Hebrew)

9. Geiger, B.; Alt, D. Haredi/Chabad Women's Acculturation Experience in a Non-Haredi Institute of Higher Education in Northern Galilee. Women Jud. Multidiscip. e-J. 2014, 11, 1-25.

10. Herzog, H.; Braude, A. Gendering Religion and Politics: Untangling Modernities; Palgrave Macmillan: New York, NY, USA, 2009.

11. Laiush, B. The Liminal Women: Haredi Women Facing Modern Change; Resling: Tel Aviv, Israel, 2014. (In Hebrew)

12. Sivan, E.; Caplan, K. Israeli Haredim: Integration Without Assimilation; Hakibbutz Hameuhad: Tel Aviv, Israel, 2003. (In Hebrew)

13. CBS (Central Bureau of Statistics Israel). Available online: http:/ / www.cbs.gov.il/ (accessed on 28 January 2022).

14. Israel Democracy Institute. Statistical Report on Ultra-Orthodox Society in Israel; Gilad, M., Lee, C., Eds.; Jerusalem Institute for Israel Studies: Jerusalem, Israel, 2021; Available online: https: / / en.idi.org.il/ (accessed on 21 January 2022).

15. Cahaner, L. Proposal to Establish the Matanel Career Center for the Ultra-orthodox (Haredi) Community at the University of Haifa; Haifa University: Haifa, Israel, 2011.

16. Hakak, Y. Between the Holy and the Purposeful: Vocational Training for Ultra-Orthodox Men; The Floersheimer Institute for Policy Studies: Jerusalem, Israel, 2004.

17. Baum, N.; Yedidya, T.; Schwartz, C.; Aran, O. Women Pursuing Higher Education in Ultra-Orthodox Society. J. Soc. Work. Educ. 2014, 50, 16-75. [CrossRef]

18. Pfefferman, B.; Malchi, A. Employment in the Haredi Sector-Special Report; The Israeli Ministry of Industry, Trade and Labor: Jerusalem, Israel, 2010. (In Hebrew)

19. May-Yazdi, O.; BenDavid-Hadar, I. The Relationships Between Income, Academic Education, and Financial Literacy: The Case of the Ultra-Orthodox in Israel. Educ. Soc. 2018, 36, 49-76. [CrossRef]

20. Gottlieb, D. Poverty and Labor Market Behavior in the Ultra-Orthodox Community; Van Leer Institute: Jerusalem, Israel, 2007. 
21. Gurovich, N.; Cohen-Kastro, E. Ultra-Orthodox Jews Geographic Distribution and Demographic, Social and Economic Characteristics of the Ultra-Orthodox Jewish Population in Israel 1996-2001; Central Bureau of Statistics-Demography Sector: Jerusalem, Israel, 2004.

22. Reimer, S. Higher Education, and Theological Liberalism: Revisiting the old Issue. Soc. Relig. 2010, 71, 393-408. [CrossRef]

23. Hurtado, S. Linking Diversity with the Educational and Civic Missions of Higher Education. Rev. High. Educ. 2007, 30, 185-196. [CrossRef]

24. Lee, J.J. Religion and College Attendance: Change among Students. Rev. High. Educ. 2002, 25, 369-384. [CrossRef]

25. Lupo, J. A Shift in Haredi Society: Vocational Training and Academic Studies; The Floersheimer Institute for Policy Studies: Jerusalem, Israel, 2003.

26. Marcus, S.; Josman, N.; Zlotnik, S. Affirmative action in Israel: Access to academia for the ultra-orthodox community. Aust. Occup. Ther. J. 2015, 62, 21-26. [CrossRef] [PubMed]

27. Novis Deutsch, N.; Rubin, O. Ultra-Orthodox women pursuing higher education: Motivations and challenges. Stud. High. Educ. 2019, 44, 1519-1538. [CrossRef]

28. Malach, G.; Kahner, L.; Regev, E. The Five-Year Plan of MALAG-VATAT for the Haredi Population Over 2012-2016, Assessment and Recommendation for the Next Five Years; MALAG-VATAT: Jerusalem, Israel, 2016. (In Hebrew)

29. Kalagy, T. Three approaches to the connection between modernisation and traditionalism: A case study of the acquisition of academic education among ultra-orthodox and Bedouin women. Cult. Relig. 2016, 17, 312-331. [CrossRef]

30. Dehan, N. Case study: The first Israeli BSW program for Haredi women students. J. Soc. Work. Educ. 2013, 49, 716-732. [CrossRef]

31. Garr, M.; Marans, G. Ultra-orthodox women in Israel: A pilot project in social work education. Soc. Work Educ. 2001, 20, 459-468. [CrossRef]

32. Segev, R.; Strauss, E. Forming an Affiliation Between Two Culturally Different Academic Institutions of Nursing Studies. SAGE Open Nurs. 2020, 6, 2377960820982146. [CrossRef]

33. Fischer, M.J. Settling Into Campus Life: Differences by Race/Ethnicity in College Involvement and Outcomes. J. High. Educ. 2007, 78, 125-161. [CrossRef]

34. Malach, G. A "Kosher" Degree-Academic Studies in the Haredi Sector. Floersheimer Studies; The Hebrew University of Jerusalem: Jerusalem, Israel, 2014. (In Hebrew)

35. Barth, A.; Ben-Ari, A. From wallflowers to lonely trees: Divorced ultra-orthodox women in Israel. J. Divorce Remarriage 2014, 55, 423-440. [CrossRef]

36. Yin, R.K. Case Study Research: Design and Methods, 3rd ed.; Sage Publications: Thousand Oaks, CA, USA, 2003.

37. Mishol-Shauli, N.; Golan, O. Mediatizing the Holy Community-Ultra-Orthodoxy Negotiation and Presentation on Public Social-Media. Religions 2019, 10, 438. [CrossRef]

38. Rashi, T. The Kosher Cell Phone in ultra-orthodox Society: A Technological Ghetto within the Global Village. In Digital Religion: Understanding Religious Practice in New Media Worlds; Campbell, H., Ed.; Routledge: Philadelphia, PA, USA, 2013 ; pp. $173-181$.

39. Rosenberg, H.; Rashi, T. Pashkevilim in campaigns against new media: What can pashkevilim accomplish that newspapers cannot? In Digital Judaism; Routledge: Philadelphia, PA, USA, 2015.

40. Campbell, H. Religion and the Internet in the Israeli Orthodox context. Isr. Aff. 2011, 17, 364-383. [CrossRef]

41. Ben-David Kolikant, Y.; Genut, S. The effect of prior education on students' competency in digital logic: The case of ultra-orthodox Jewish students. Comput. Sci. Educ. 2011, 27, 149-174. [CrossRef]

42. Assouline, D.; Dori-Hacohen, G. Yiddish across borders: Interviews in the Yiddish ultra-orthodox Jewish audio mass medium. Lang. Commun. 2017, 56, 69-81. [CrossRef]

43. Golan, O.; Campbell, H.A. Strategic management of religious websites: The case of Israel's orthodox communities. J. Comput. Mediat. Commun. 2015, 20, 467-486. [CrossRef]

44. Schupak, E.B. An ultra-orthodox woman performing difference in Israeli academia. Int. J. Qual. Stud. Educ. 2021, 1-20. [CrossRef]

45. Novis Deutsch, N.; Lifshitz, C. Integrating Conservative Religious Minorities into Higher Education: Praxis, Identity and Value Challenges of Teaching Ultra-Orthodox Female Religious Students from the Teacher's Perspective. Teach. High. Educ. 2016, $16,485-500$.

46. Bowman, N.A.; Smedley, C. The Forgotten Minority: Examining Religious Affiliation and University Satisfaction. High. Educ. 2013, 65, 745-760. [CrossRef]

47. Mayhew, M.J.; Bowman, N.A.; Rockenbach, A.B. Silencing Whom? Linking Campus Climates for Religious, Spiritual, and Worldview Diversity to Student Worldviews. J. High. Educ. 2014, 85, 219-245.

48. Ron, R.E. Creative consumption of modesty: The wig in a Jewish Israeli ultra-orthodox community. In Feminist Interrogations of Women's Head Hair; Routledge: Philadelphia, PA, USA, 2018; pp. 176-190.

49. Small, J.; Bowman, N. Religious Commitment, Scepticism, and Struggle among US College Students: The Impact of Majority/Minority Religious Affiliation and Institutional Type. J. Sci. Study Relig. 2011, 50, 154-174. [CrossRef]

50. Rubin, O.; Novis-Deutsch, N. Profiles of Haredi Women Pursuing Higher Education: A Cluster Analysis of Diverse Patterns of Motivations and Concerns. Megamot J. Behav. Sci. 2017, 52, 109-140. (In Hebrew)

51. Golan, O.; Mishol-Shauli, N. Fundamentalist web journalism: Walking a fine line between religious ultra-Orthodoxy and the new media ethos. Eur. J. Commun. 2018, 33, 304-320. [CrossRef]

52. Shahar, R.N.B.; Lev-On, A. Gender, religion and new media: Attitudes and behaviors related to the Internet among Ultra-orthodox women employed in computerized environments. Int. J. Commun. 2011, 5, 21. 
53. Goldfarb, Y. Does God want me to be a teacher? Motives behind occupational choice of Israeli ultra-orthodox women. J. Career Dev. 2018, 45, 303-314. [CrossRef]

54. Longman, C. Sacrificing the career or the family? Orthodox Jewish women between secular work and the sacred home. Eur. J. Womens Stud. 2008, 15, 223-239. [CrossRef]

55. Wieselmann, J.R.; Dare, E.A.; Ring-Whalen, E.A.; Roehrig, G.H. "I just do what the boys tell me": Exploring small group student interactions in an integrated STEM unit. J. Res. Sci. Teach. 2020, 57, 112-144. [CrossRef]

56. Zachmann, K. Women in STEM: Female Role Models and Gender Equitable Teaching Strategies. Sophia, the St. Catherine University Repository, Master of Arts in Education Action Research Papers. 2018. Available online: https://sophia.stkate.edu/ maed/272 (accessed on 28 January 2022). 